\title{
Chapter 4 \\ Theory of Money: From Ancient \\ Japanese Copper Coins to Virtual \\ Currencies
}

\author{
Makoto Yano
}

Currently, virtual currencies are targets of speculative activities and subject to many other problems. If, however, an ideal virtual currency can be realized, it is expected that it will add a whole new dimension to our economic activities.

Virtual currency is very similar to deposit currency in that data is used as money. While deposit currencies are centrally controlled by banks and other financial institutions, virtual currencies are maintained in a decentralized manner by many people. Through decentralization, significant cost savings can be realized.

To evaluate the potential of virtual currencies, it is necessary to understand what a currency is as opposed to money, what divides banknotes from deposit currency, and what separates virtual currency from deposit currency. This chapter covers these issues by introducing a new theory of money.

\section{History of Money: From Commodity Money to Virtual Currency}

To understand the innovations that virtual currencies have brought, and are expected to bring to our society, it is desirable to study various types of currencies that were

\footnotetext{
This article is based on my final report to the study group "Blockchain and Society 5.0 - The Creation of a New Marketplace based on Distributed Consensus" at the Research Institute of Economy, Trade, and Industry (RIETI) . I am grateful to all the participant in the study group and also to Fumio Dei and William Metcalfe for valuable comments on earlier versions of this chapter. The author gratefully acknowledges the financial support of a Grant-in-Aid for Scientific Research (A) (\#16H02015) from the Japan Society for the Promotion of Science.
}

M. Yano (ख)

Research Institute of Economy, Trade and Industry (RIETI), Tokyo, Japan

e-mail: yano-makoto@ rieti.go.jp 
used in the past and that are used currently, and compare them with virtual currencies. For this purpose, it is useful to start with the history of Japanese money.

\subsection{History of Japanese Money}

In Japan, twelve kinds of copper coins (called the imperial coins) were cast over the period between $708 \mathrm{AD}$ and $963 \mathrm{AD} .{ }^{1}$ After that, however, government-made money was not cast again until the era of Toyotomi Hideyoshi (1537-1598) who, in the 1580s, united Japan after a century-long period of war.

This is partly because most Japanese copper was not suitable for coins because it contained too much sulfur. ${ }^{2}$ Instead, Chinese copper coins were imported from China between the middle of the twelfth century through to the fifteenth century. Kiyomori Taira (1118-1181) and Yoshimitsu Ashikaga (1358-1408) led trade with the Song Dynasty (960-1279) and the Ming Dynasty (1368-1644), respectively. A main target of trade was Chinese copper coins. It is known that in the fifteenth century, copper coins circulated rather widely; tolls for bridges and fees for inns were paid in copper coins. $^{3}$

Hideyoshi Toyotomi cast the famous first Japanese gold coin, called Tensho Oban, in $1588 .{ }^{4}$ Soon after his death, Iyeyasu Tokugawa (1543-1616) took power in 1600 and cast new gold coins called Keicho Oban and Koban. During the Tokugawa era, various coins were cast and circulated widely.

The first paper money was printed in 1610, which promised payback in silver coins. Subsequently, many local governments printed paper money that promised payback in gold and silver coins. ${ }^{5}$

\subsection{Paper Money}

The modern economy is built on paper money. The era of paper money can be divided into two subperiods. The first subperiod was that in which paper money was convertible into gold whereas the second period is that of nonconvertible money. To understand how the two types of money have developed, it is useful to look into the history of American money.

\footnotetext{
${ }^{1}$ Wadokaichin in 708 , is said to be the first Japanese copper coin that was minted for circulation as a medium of exchange. It is known that several earlier coins were minted although they were considered to be not for circulation; e.g., see Takizawa (1996, Chap. 1) and Takagi (2016, p. 10).

${ }^{2}$ See Mikami (1996, p. 6).

${ }^{3}$ See Mikami (1996, p. 9).

${ }^{4}$ Prior to Tesho Oban, some gold and silver coins were minted in the first half of the sixteenth century. However, they were not for circulation but for gifts. During the latter half of the sixteenth century, gold bullion was used for transactions. For details, see Takagi (2016, p. 66).

${ }^{5}$ See Takizawa (1996, p. 253) and Takagi (2016, p. 113).
} 


\subsubsection{Gold Standard}

Until the mid-1930s, in the United States, the government guaranteed the conversion of dollar bills for gold, which is called the convertible currency system. Immediately after independence, under the 1792 Coinage Act, the $\$ 10$ coin was legally defined to contain 16.04 grams of pure gold (in other words, 1 troy ounce of gold $=\$ 19.319$ ). Subsequently, the amount of gold was reduced to 15.05 grams under the Coinage Act of 1837 (1 troy ounce of gold = \$20.67). Then, in 1900, the Gold Standard Act was passed that set gold as the only standard for redeeming paper money. This conversion rate was kept until 1933.

In the middle of the nineteenth century, there were times when state governments, cities, commercial banks, and various companies issued dollar bills that were convertible for gold and government bonds. Under such a system, once a bank got into financial trouble, many people demanded withdrawal of deposits at once. Such a bank would be doomed to fail because no bank could satisfy a massive demand for withdrawal. That triggered withdrawal demands for other banks which stalled the monetary system as a whole. This phenomenon is called a "bank run."

To deal with this problem, the USA adopted the Federal Reserve Act of 1913. Under this act, the Federal Reserve Bank was designated as the bank for issuing money called Federal Reserve Notes. Federal Reserve Notes gradually replaced various banknotes issued by the government and commercial banks. During this time, consistently, 1 troy ounce of gold was fixed at \$20.67.

The collapse of the New York Stock Exchange in 1929 triggered a number of corporate bankruptcies and 744 banks failed in the first 10 months alone. After that, the crisis prolonged, and the economic stagnation continued until 1945, when World War II ended. This is the period called the Great Depression.

In 1932, the Pecora Committee, led by Ferdinand Pecora, was created in the Senate to investigate the causes of the Great Depression. Through the Commission's investigation, it was revealed that during the Great Depression, various shady transactions were conducted. One of the major causes of the Great Depression is that book operations such as reassignment of losses were conducted between banks and their securities subsidiaries and between securities firms and their banking subsidiaries.

\subsubsection{Fiat Money System}

In the first half of the 1930s, various institutional reforms of the financial market took place to cope with the Great Depression. Of particular importance were the following:

1. Abolishment of the gold standard

2. Creation of the Federal Deposit Insurance Corporation

3. Separation of securities companies and commercial banks

4. Introduction of the information disclosure system to the stock market. 
These reforms were to ensure the stability of the banking system and to increase the transparency of the financial market as a whole. Nowadays, all developed countries have adopted much the same financial system. In what follows, the first three reforms are explained, and these are directly related to the monetary system based on fiat money.

Abolishment of the Gold Standard: A decline of a country's economic health makes it difficult for the country to maintain the gold standard. In the USA in 1934, most private possession of gold was outlawed by the Gold Reserve Act of 1934; all individuals who owned gold were required to sell it to the Department of Treasury. The Act devalued the dollar against gold, changing \$20.67 per troy ounce to $\$ 35$.

Creation of the Federal Deposit Insurance Corporation: Once a bank run occurs, as discussed above, it becomes highly difficult for the bank to hold enough cash to cover all demands for withdrawals. If banks can insure against such a risk, the banking system will become more stable. With such a consideration, in 1933, the Federal Deposit Insurance Corporation (FDIC) was established. For the banks that were members of the FDIC, a certain amount of a customer's deposit was covered by insurance in the case of a bank failure.

Separation of securities companies and commercial banks: The Glass-Steagall Act was established in 1933, separating the operations of securities companies and commercial banks. Securities can be thought of as certificates that the issuer promises to pay for future earnings. Selling securities implies that the purpose is to invest in the issuer's business. A securities company is an intermediary that facilitates issuances and resellings of securities. Commercial banks provide settlement mediation services to facilitate payments between account holders. Under the Glass-Steagall Act, commercial banks are dedicated to settlement mediation, and securities firms are concentrated on investment mediation.

\subsection{Ledger Currencies}

Nowadays, records on bank accounts are kept in the form of digital data. As bank deposits show, payment records on bank account can play the role of a currency, which is called a deposit currency. Virtual currencies on the blockchain are also records of transactions in the form of digital data. As this shows, digital transaction data can be used as a currency if the records are accurate and cannot be tampered with.

A ledger is a "book of permanent record." It is safe to assume that "permanent" in this definition implies both "accurate" and "unfalsifiable." Because both deposit and virtual currencies are kept in the form of a ledger, they may be called ledger currencies. 


\subsubsection{Deposit Currency: Centralized Data Currency}

The most familiar examples of deposit currencies are checking accounts in the USA. Instead of writing a check, nowadays, many people use electronic fund transfers by which money can be transferred online at a very low cost. Deposit currencies started changing our daily life in the late 1970s to the early 1980s. During that period, salaries started to be directly deposited into workers' accounts, whereas before that, people were paid in checks and cash.

Theoretically, a bank can offer a deposit currency to its customers by keeping track of all transactions from one account to another and making sure that a payment from an account at a particular point in time does not exceed the balance at that point in time. The transactions are lined up according to time. Once that record is built, it is easy to extract transactions that are related to a particular account.

Cash is an IOU that stipulates the society owe the holder of cash the purchasing power equal to the value of the IOU. A deposit in a bank account is the bank's IOU to the account holder. It is therefore no wonder that a bank deposit serves as a currency to the extent to which the bank's IOU is trusted by account holders.

Currently, deposit currencies are purely supplementary to paper money. In other words, the system of bank deposit accounts functions as money because customers trust banks to pay cash back whenever they demand withdrawals.

\subsubsection{Virtual Currency: Decentralized Ledger Currency}

Virtual currency is a new type of ledger currency in which trust is ensured by a mechanism completely different from deposit currency. Deposit currency, which is a traditional ledger currency, is managed centrally by the bank. Many workers' efforts are put into maintaining the integrity of transaction records, which creates trust in those records. Virtual currency, in contrast, maintains the integrity of data by a computer algorithm that involves many people in a decentralized manner creating transaction records. The integrity of the data is maintained neither by a single institution nor a single individual but an algorithm itself together with the many people who independently process data through the algorithm.

What is difficult on the Internet is how to link one account with another, how to keep payment/receipt records between accounts, how to ensure accuracy, and how to create a ledger that will never be tampered with. Blockchain technology, on which many virtual currencies are based, is the first technology to show that these difficulties can be overcome on the Internet in a completely open and decentralized manner. ${ }^{6}$

\footnotetext{
${ }^{6}$ For a more detailed explanation, see Omote and Yano (2020).
} 


\section{Money and Its Function}

What role does money play in the economy? It is important to address this question before discussing the role of virtual currency. Money has three basic functions: a scale of value, a medium of exchange, and a store of value.

A transaction is an activity to set conditions for an exchange and then to carry out the exchange. To make an exchange, it is necessary to evaluate what value a particular good has. For such an evaluation, a scale of value is necessary against which the good can be measured. It is necessary that a scale must allow for the four arithmetic operations of addition, subtraction, multiplication, and division; without this capability, no two goods can be measured against each other.

A medium of exchange means the function that synchronizes the timing of transactions. Think of a person who expects to acquire a lot of apples tomorrow and wants to exchange some apples for oranges. He happens to meet a person today who has a lot of oranges and has to leave the town tonight. Money facilitates an exchange in such a case; the person who will soon have apples can pay money for oranges, and the other person can spend the money he receives to buy apples later. This is an example showing that money, as a medium of exchange, fixes the intertemporal misalignment of transaction opportunities. Next, think of three people who live in totally different places and cannot meet at one place; the first is an orange eater owning apples, the second is a grape eater with oranges, and the third is an apple eater with grapes. In this state, it is extremely difficult for each person to get what he/she likes by exchanging goods. Money can facilitate an exchange in such a case as well. If, for example, the orange eater has money, he can buy oranges from the grape eater (second person), who has oranges. The grape eater can use this money to buy grapes from the apple eater (third person), who owns grapes. Finally, the apple eater can use the money to buy apples from the orange eater (first person), who owns apples. In this way, money returns to the first person, who initially owned it; everyone gets what he/she wants to eat. This is an example showing that money, as a medium of exchange, fixes the spatial misalignment of transaction opportunities. These examples show that money can serve as a medium of exchange because everyone knows that others accept money for goods.

As a store of value, money lets its owner save purchasing power until the need emerges to purchase goods and services. This is a function that a medium of exchange must possess to fix the misalignment of transaction opportunities. A material that is highly perishable, such as ice cream, can never serve as a medium of exchange.

To use a particular good as money, it must possess all three functions of money. Since diamonds are wanted by everyone and do not decay, they are good for a medium of exchange and a store of value. However, diamonds are not suitable for the four arithmetic operations. If a diamond were divided into two pieces, its value would substantially decrease. The divided pieces cannot be put back together. This implies that diamonds are unsuitable as a scale of value.

Radioactive substances such as uranium may be good for a scale of value and a store of value. However, it is too dangerous to carry around in small portions, which 
implies that uranium cannot serve as a medium of exchange. Iron is very good for a scale of value and a medium of exchange. However, iron rusts too quickly to be a store of value in comparison with copper, which explains why, historically, copper coins have been more common than iron coins.

\section{Transaction Costs and Money}

History shows that a new type of money was, and is right now, introduced when it can economize the existing transaction costs by raising trust in money. ${ }^{7}$ This has contributed to the creation of an economy with a higher quality market economy. In this section, I will examine this process.

\subsection{Commodity Money}

What materials are good for money? The first answer that comes to mind is precious metals such as gold and silver. Because everyone wants these precious metals and can carry them in small portions, it is perfect as a medium of exchange. Because those precious metals do not lose their values easily, they are good for a store of value. Moreover, these metals can easily be divided into small pieces and melted into a big chunk. This implies that they are good for the four arithmetic operations.

One problem of these precious metals is that they are too precious. This implies that they are not suitable for small transactions. Copper is a metal that is more suitable for small transactions. Because copper does not rust as quickly as iron, copper coins have been widely used for many centuries. In addition, copper has been in daily use for tools and ornaments.

Previously, real goods such as silk, barley, or rice were used as a medium of exchange. Although they are far more fragile than precious metals, it may be that they were more acceptable for many ordinary traders as a medium of exchange in the world in which gold, silver, and copper were not readily available.

\subsection{Currency and Transaction Costs}

Unlike commodity money, there are types of money the value of which is not directly linked to the use of goods. That is the currency. Whether it is a banknote or a ledger currency, its value stems from the fact that they are accepted as money by people. In other words, a currency plays the role of money supported by the trust of the

\footnotetext{
${ }^{7}$ For market quality theory, see Yano (2019), which focuses on different types of transaction costs for newly developing markets.
} 
people. As discussed above, how trust in currency is created differs between paper money, deposit currencies, and virtual currencies. Paper money is backed up by a government's monetary policy, deposit currencies are backed by the operation of banks, and virtual currencies are backed by decentralized algorithms.

A shift away from commodity money to a currency may be explained by a reduction of the transaction cost associated with the use of commodity money. If rice or silk is used as a means of exchange, its quality as a commodity can deteriorate easily; rice could become inedible; silk could become worn out. The value of gold and silver does not deteriorate easily. However, they are too precious for small transactions and can become an easy target for robbers.

This explains why paper money was invented as soon as a precious-metal standard was established. Deposit currencies were adopted to economize costs of handling cash.

As this shows, a currency has been developed to economize transaction costs. In other words, a choice of a currency is determined by a comparison in transaction cost between the existing money and an alternative currency that may be newly developed.

\subsection{Ledger Currencies and Transaction Costs}

The cost of maintaining a deposit currency is rather high. This can be easily understood by thinking of the numbers of banks, their branches, and people working there. Many people are excited about virtual currencies because they expect virtual currencies to economize that cost significantly. This may be explained by comparing a traditional encyclopedia and Wikipedia.

Previously, many families had a set of encyclopedias, in which experts explain their respective subjects, covering social phenomena, historical facts, and scientific knowledge. The process of putting an encyclopedia together may be called "centralized knowledge processing" just like centralized network computing. The editorial board of an encyclopedia is responsible for centrally controlling the selection of authors for all subjects. Although all subjects are explained by experts, they are checked by the editorial board, which is responsible for making sure that all explanations are correct and trustworthy. In other words, the editorial board acts as if it is the central server of a centralized network.

In contrast, Wikipedia is based on "decentralized knowledge processing." Every Wikipedia article is written by an expert or multiple experts. However, no authority exists who is trusted to check whether articles are correct. Instead, all users check articles, add explanations, if needed, and correct errors if present.

The decentralized knowledge processing introduced by Wikipedia has its drawbacks. Sometimes, we see some errors in an explanation because there is no centralized trusted authority that checks the articles. Some explanations are too technical for ordinary people to understand.

A strong merit of Wikipedia is to utilize human altruism or the urge to share information accurately to build something useful for the society. If you have the charitable 
mindset to share accurate information with society, and you have confidence in your expertise, you will be tempted to write an article for Wikipedia. It requires considerable effort for a person to write an article that ordinary people can understand. If you write a fake article, someone else will soon find out and rewrite it. This minimizes the incentive to contribute wrong and/or inaccurate information.

In short, Wikipedia has effectively utilized the human urge to explain and share knowledge. Thanks to this mechanism, it has succeeded in creating a decentralized encyclopedia with a huge content at a very small cost.

In many respects, blockchain is similar to Wikipedia. It does not use a centralized management system. Except for setting the minimum protocol, there is no centralized control, and the evaluation of information is decentralized and left to a large number of anonymous participants. It maximizes the willingness of well-meaning people to make accurate records and decentralizes the protection against malicious attacks. Through such design, virtual currencies offer money at a lower cost than the expensive system of centralized deposit currencies.

\subsection{Cost Structure of Different Currencies}

Figure 1 illustrates the difference between paper money and ledger currencies and that between deposit and virtual currencies. For each plot, the vertical axis represents the price of money. The price of money is represented by the nominal interest rate. The left-most panel explains the cost (marginal cost) of paper money in relation to its price. The cost of printing a bill can be assumed to be negligible. No matter how many dollar bills are printed, the cost of printing an additional bill may be assumed to be constant. The price of paper money is determined at a level much higher than the marginal cost.

In the middle and right-most panels of Fig. 1, the marginal cost curve for creating a ledger currency is an upward-sloping line. This is because the additional cost of increasing the currency supply, either in deposit or virtual currency, becomes larger
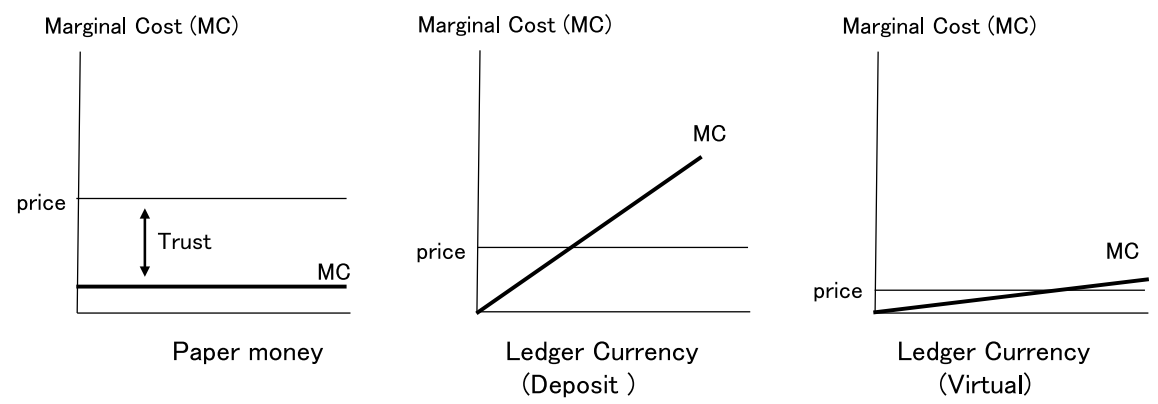

Fig. 1 Cost structure of currencies 
as the supply increases. However, as noted above, it may be assumed that the cost of creating a virtual currency is much smaller.

In these simple cases, it is known that the marginal cost curve and the supply curve are identical. Therefore, as shown in the middle and right panels, the supply of a ledger currency is determined at the intersection between the price of a currency and the marginal cost curve. In contrast, as the left-most panel of the figure shows, in the case of paper money, the supply of a currency is determined by the government's monetary policy; there is no relationship between the unit price of money and the marginal cost curve.

\section{New Monetary Theory for the Digital Era}

To explain the use of virtual currencies economically, it is necessary to create a new monetary theory that shows what the difference in cost structure in Fig. 1 means. ${ }^{8}$ The following provides a brief explanation of this theory. For this purpose, it is useful to return to the Japanese history of money, the overview of which is provided in Sect. 1 of this chapter. This is because, for more than a thousand years, the Japanese monetary system has evolved rather naturally without being disturbed by foreign influences.

\subsection{An Economy with Commodity Money Only}

As explained in Sect. 1 of this chapter, copper coins were introduced to Japan from the twelfth century through to the middle of the sixteenth century. During that period, Chinese copper coins and gold were used as a medium of exchange along with real goods such as silk and rice. ${ }^{9}$

To describe this system, the left-hand side panel of Fig. 2 illustrates the market for gold, and the right-hand side panel shows that for copper coins. The vertical axis represents the unit prices of gold and copper coins in units of goods and services, which are denoted as $Q$ and $P$, respectively. If the supplies of gold and copper coins are assumed to be fixed, they can be illustrated by vertical lines in those panels. The demands for gold and copper coins are illustrated by curves $G$ and $C$. The equilibrium prices for gold and copper coins are determined at the intersections between demand and supply curves, which are $Q$ for gold and $P$ for copper coins. For the sake of simplicity, assume that the exchange rate of gold to copper was $1-4$ (or $Q=4 P$ ).

\footnotetext{
${ }^{8}$ For conventional monetary theory, see Niehans (1978), Iwai (1993), Kiyotaki and Wright (1989), and Rocheteau and Wright (2005).

${ }^{9}$ The use of goods such as rice, cotton, dye, and silk as money has been recorded since the eighth century. See Takizawa (1996, p. 2).
} 


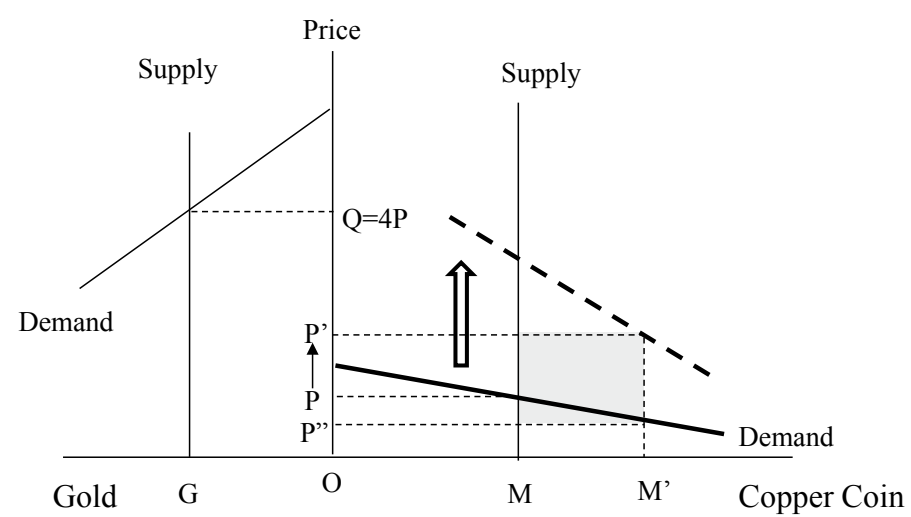

Fig. 2 Real commodity money and Nobunaga's alchemy

\subsection{Nobunaga Oda's Currency Policy}

Nobunaga Oda (1534-1582) was a feudal lord who almost unified Japan towards the end of a warring period of more than one hundred years(1467-1587). After his death, his conquest was succeeded by one of his leading generals, Hideyoshi Toyotomi, who united the entirety of Japan in 1587.

It is arguable that Nobunaga Oda is the first person who tried and succeeded in converting the commodity money economy into a currency economy in Japan. Oda actively promoted the use of copper coins; his battle flag had three pictures of a Ming Dynasty Chinese coin called Eiraku-tsuho. ${ }^{10}$ In 1569 , Oda adopted the law stipulating the exchange rates for gold, silver, and copper coins at 1 ryo (about 16.5 grams) of gold equal to 7.5 ryo of silver and to 1.5 kanmon of copper coins (mon is the basic counter for copper coins and 1000 mon is 1 kanmon). ${ }^{11}$

More importantly, Oda set the exchange rates among various grades of copper coins. ${ }^{12}$ At that time all sorts of copper coins circulated, including old Japanese coins, those imported through Song and Ming trade, and privately minted coins from both China and Japan. The imported copper coins included Tang, Song, and Ming dynasty coins even during the Ming period. ${ }^{13}$ Many of those coins were broken in half and worn out. It is documented that before Oda, there were many quarrels because of refusals to accept those low copper coins. Oda sets four grades copper, including

\footnotetext{
${ }^{10} \mathrm{See}$ https://samurai-world.com/oda-nobunagas-crests/.

${ }^{11} \mathrm{~A}$ record exists as early as the first half of the eighth century that the government set an exchange rate between silver coins and copper coins; see Takizawa (1996, p. 3). Before Oda, various local lords set exchange rates between different grades of copper coins. Nobunaga Oda's innovation is that he set an exchange rate between gold (bullion) and copper coins; see Takizawa (1996, Chap. 3) and Takagi (2016, Chap. 2).

${ }^{12}$ See Okuno (1969, pp. 256, 257).

${ }^{13}$ For example, the majority of the excavated old coins are Song dynasty coins with some Tang and Ming coins. See Takizawa (1996, p. 63, Table 4).
} 
broken coins (third degree) and privately minted (fourth degree) and related their values to that of gold. ${ }^{14}$

Nobunaga Oda defeated many feudal lords and in doing so he collected large quantities of gold, silver, and copper coins. As explained in the next section, Oda's policy was to create a currency, from which he obtained a large amount of purchasing power. We refer to this policy as Oda's alchemy. Before describing this policy, the reader must appreciate that the following discussion is purely a theory that may or may not reflect Nobunaga Oda's actual intention.

\section{3 “Nobunaga's Alchemy"}

To describe the effect of Nobunaga Oda's policy back in the sixteenth century, we consider a fictitious world that is ruled by an absolute monarch called "Nobunaga." He possesses a large number of gold and copper coins. Everyone knows that he never breaks his promises. The economy before Nobunaga is described by Fig. 2; the exchange ratio of gold and copper is four copper coins to one unit of gold $(Q=4 P)$. In that economy, copper coins and gold are not highly substitutable. Those who use copper coins for transactions are basically separated from those who use gold for transactions. There are many people who only use copper coins. They are vaguely aware of the exchange rate between copper coins to gold. However, they do not know if and where they can actually exchange their copper coins for gold at the exchange rate. Under these circumstances, it can be assumed that the price of copper coins primarily reflects the use of copper as a commodity.

Suppose that, in this state, Nobunaga raises his official value of copper coins to one unit of gold for two copper coins $(Q=2 P)$. This revaluation of copper coins implies that gold has become cheaper. If Nobunaga were an ordinary, untrustworthy lord, a large amount of gold would leave his hands because people would substitute copper coins for gold. A large volume of copper coins would consequently accumulate in the hands of Nobunaga. The price of copper coins would fall, which would make it impossible to support the artificially raised price of copper coins.

If, however, Nobunaga were an absolute ruler, and people trust whatever Nobunaga says, then he can raise a large volume of funds with which he can purchase goods, soldiers, and other workers. Why?

Because people hold copper coins to use as a medium of exchange and because they believe that Nobunaga will never break his promise. If people trust that he will never break his promise, as money, copper coins are just as good as, or even better than, gold. As a usual commodity, of course, copper is still not as valuable as gold. As a scale of value, however, they will become exactly the same.

\footnotetext{
${ }^{14}$ Nobunaga Oda was not the first to introduce a rule on low-quality coins. However, historians report that he was the first to determine clear exchange rates between low-quality coin; see Takizawa (1996).
} 
Assume that before Nobunaga revalues copper coins, copper coins and gold served different purposes as a medium of exchange; copper coins were for daily goods whereas gold was for highly valuable goods. People who used copper coins for transactions did not know how and where they could exchange their copper coins for gold; they knew only vaguely that gold was much more valuable than copper coins.

Once the fictitious ruler revalues copper coins and declares that he will exchange copper coins for gold at the declared rate, two copper coins will become the same as one unit of gold as a store of value. Both as a medium of exchange and as a store of value, copper coins will become more valuable than one half unit of gold because copper coins have now become twice as valuable as before and because Nobunaga's guarantee on the exchange rate reduces the uncertainty that copper coins were subject to in the previous economy. To simplify this explanation, we assume that the revaluation of copper coins will not affect the gold market, illustrated on the left-hand side panel. That is, the price of gold will stay at $Q$.

All these suggest that we may safely assume that after the revaluation, the demand (willingness to pay) for copper coins will become more than twice as much as before. In Fig. 2, the new demand for money is illustrated under the assumption that the demand becomes three times as high; that is, the dotted curve is three times as high as the original demand curve on the right-hand side panel.

Then, the upward shift of the money demand curve will create an excess demand for copper coins. Because people believe that Nobunaga will honor his promise to exchanging one unit of gold for two copper coins, he will be able to keep his promise to maintain the price of copper coins at $P^{\prime}=2 P$ by releasing his copper coins, of which we assume that he owns many. At $P^{\prime}$, the demand for copper coins is $M^{\prime}$. Thus, he will raise money by as much as $2 P^{\prime}\left(M^{\prime}-M\right)$, which he can then use to purchase goods and soldiers. This is what we call "Nobunaga's alchemy."

If Nobunaga were not to conduct the "alchemy" and released copper coins by as much as $M^{\prime}-M$, the price of copper coins would fall along the original money demand curve to $P^{\prime \prime}$. In this respect, the gain from the "alchemy" may be thought of as $\left(P^{\prime}-P^{\prime \prime}\right)\left(M^{\prime}-M\right)$.

\subsection{Monetary Policy of Nobunaga Oda and Hideyoshi Toyotomi}

As the above analysis shows, what makes "Nobunaga's alchemy" possible is the trust that he enjoys from people. This trust is the source that turns totally valueless materials, such as worn-out copper coins, into something as valuable as gold.

A historical fact is that in 1569, Nobunaga Oda adopted his exchange rates of gold, silver, and various grades of copper coins at 1 ryo of gold $=7.5$ ryo of silver $=1.5$ kanmon of copper coins. It is known that before this policy was introduced, it was recorded that 1 ryo of gold equaled 10 ryo of silver and 2 kanmon of bronze 
coins. If the latter exchange rates were held until Nobunaga Oda's days, his 1569 policy is a revaluation of silver and copper coins against gold. ${ }^{15}$

To implement such a policy, it is absolutely important that people believed that Oda could keep his promise unconditionally. To create such a trust, what did Oda need to do?

The answer would be to let people know that he had a huge amount of gold to back up his promise. In fact, it is known that the top floor of his castle, built in 1578 and visible to everyone, was plated with gold (Frois 1593). Hideyoshi Toyotomi, who took over Oda's position after he was killed in 1582, announced that he would maintain Oda's monetary policy. He then revalued the low grade copper coins by setting 1 ryo of gold equal to 2 kanmon of low grade coins; in contrast, Oda had set 1 ryo of gold equal to 1.5 kanmon of high quality gold coins.

Toyotomi built the famous golden portable tea house used to entertain the emperor and he invited town people for tea at the tea house set in a big Kyoto shrine. The large gold coins that Toyotomi minted were for gifts and it was well known that he owned a huge amount of gold. It makes a lot of sense if the purpose of Nobunaga and Toyotomi's showy use of gold was to gain people's trust in the currency (copper coins) that they wanted to use effectively.

\subsection{Paper Money System}

The theory of currency creation in the previous section assumes the existence of two types of goods. One of them is a real good that is intrinsically more valuable than the other good, which is to be used as a currency. The theory shows that a trusted government can create a currency (and profit from it) by revaluating the less valuable commodity against the more valuable one. This captures a general feature on creation of all types of currencies except virtual currency.

Figure 2 may be interpreted as a model capturing the gold standard system. For that purpose, it suffices simply to reinterpret the right-hand side panel as a market for paper money.

It is also possible to interpret Fig. 2 as a model of the fiat money system. For that interpretation, the left-hand side panel may be thought of as a market for financial assets. Under the Glass-Steagall Act, private banks and securities houses were, respectively, restricted to participate only in the money market and the securities market. The central bank was, in contrast, the only financial institution that was permitted to participate in both markets. The value of a currency (paper money) was controlled by the central bank, which was, and still is, authorized to intervene in both markets. If, just like "Nobunaga" in Fig. 2, the central bank can fix the exchange rate of paper money against financial assets within a certain range, the fiat money system can be sustained. Such a policy has been called an open market operation, which we do not often hear about anymore (Fig. 3).

${ }^{15}$ See Takagi (2016, p. 74). 


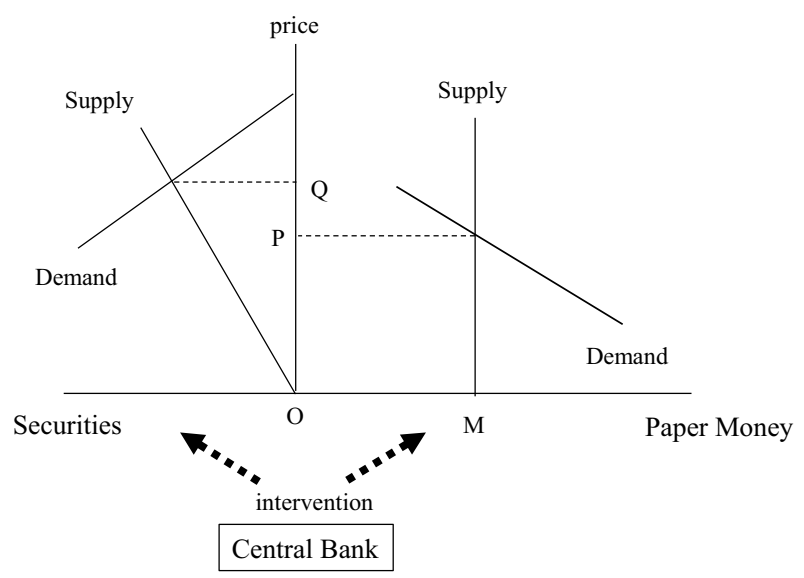

Fig. 3 Fiat Money and Glass-Steagall

The Glass-Steagall Act, which separated the stock market and the currency market, was abolished in 1999. This stopped any restriction on combining the money market and the financial market. Because the institutional separation between banks and securities firms was lost, the financial market has become a place for a two-player money game between the central banks and private financial institutions. Without going into great detail, it may be considered that the repeal of the Glass-Steagall Act led to the Global Financial Crisis in 2008. In this respect, it is understandable that the birth of Bitcoin is attributed to the financial crisis as discussed in Chapter 3.

\subsection{Deposit Currency to Virtual Currency}

The modern economy is built on a financial system based on banknotes and deposit currencies. Is it possible to convert it to an economy based on virtual currency?

To answer this question, it is necessary first to describe the economy with both paper money and a deposit currency. For this purpose, in Fig. 4, the marginal cost curve of the deposit currency is drawn as a straight upward curve starting from $M$ in the figure. If the amount of paper money is $M$, then the supply of the entire currency is also indicated by the same straight line. If the deposit currency is provided to an economy where only banknotes circulate, the unit price of the currency will drop from $P$ to $P^{\prime}$.

According to economic theory, the benefits that the whole economy receives from money creation are indicated by the area between the demand curve and the supply curve. In other words, the introduction of a deposit currency into the economy with only paper money (described in Fig. 2) benefits the society by the area of the light-gray triangle. 


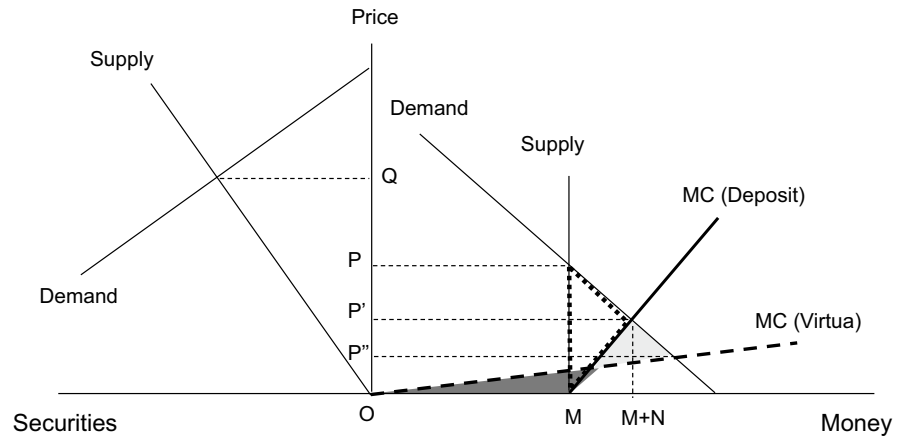

Fig. 4 Deposit and virtual currency equilibria

Next, let us focus on the marginal cost of a virtual currency shown by the dotted line in Fig. 4. Now suppose that the monetary system shifted from using currency and paper money to one using only virtual currency. In that case, the equilibrium is determined at the intersection of the currency demand curve and the marginal cost curve of the virtual currency. As the figure shows, this shift benefits the economy by the light-gray triangle in the figure and harms it by the dark-gray triangle.

In Fig. 4, the marginal cost curve of the virtual currency is drawn in such a way that the areas of these two triangles are equal to each other. This implies that if the marginal cost curve of the virtual currency is lower than the dotted line, switching to the virtual currency system will benefit the whole of society.

In short, if a virtual currency can economize the transaction cost necessary to maintain deposit currencies sufficiently, it can take over the entire currency system. If that happens in the future, an economy without a central banking system will develop.

\section{References}

Frois L (1593). Historia de Japam, available in Japanese translation, Nihonshi, 12 vols, translated by Matsuda and Kawasaki, Chuoukoronsha

Iwai, K (1993) Monetary theory, in Japanese, Kaheiron, Chikuma

Kiyotaki N, Wright R (1989) On money as a medium of exchange. J Polit Econ

Mikami R (1996) The story of money in Edo, in Japanese, Edo no KaheiMonogatari, Toyokeizai

Niehans J (1978) The theory of money

Okuno T (1969) Research on Nobunaga Oda documents, vol. 1, in Japanese, Oda Nobunaga Bunsho no Kenkyu, Jou, Yoshikawa Kobunkan

Rocheteau G, Wright R (2005). Money in search equilibrium, in competitive equilibrium, and in competitive search equilibrium. Econometrica

Takagi H (2016) Japanese history of currencies, in Japanese, Tshuuka no Nihonshi, Chuoukoronsha Takizawa T (1996) History of the Japanese money, in Japanese, Nihon no Kahei no Rekishi, Nihon Rekishi Gakkai 
Yano M (2019) Market quality theory and the Coase theorem in the presence of transaction costs, RIETI DP19-E-097

Makoto Yano is Chairman of the Research Institute of Economy, Trade and Industry (RIETI); he is also a specially appointed professor at Kyoto University, Jochi University, and Chubu University. He is an internationally known researcher who has made a number of substantial contributions in international trade, market theory, and especially on economic dynamics. His contributions in economic dynamics, for example, are represented by articles in Econometrica in 1995 and the Journal of Economic Theory in 1996, which explained the conditions under which general economic equilibrium shows chaotic behavior. His 1998 Econometrica article is recognized as the latest most important work on the characterization of dynamic general equilibrium.

Besides those rather theoretical works, Prof. Yano has also provided influential insights on contemporary real-world phenomena. Those include transfer problems (American Economic Review, 1999), voluntary export restraints (International Economic Review [IER], 1995), and trade conflicts (IER, 1998), on which there have been a number of follow-up papers.

His recent research on "market quality" addresses various problems in modern economies, including the financial market crisis since 2008 and the recent nuclear accidents in Japan, from the point of view of market quality - a new economic concept that Prof. Yano has developed and is applying to Japanese and international markets. Concerning quality of competition, quality of information, and quality of products, market quality is defined as an index jointly determined by the efficiency of an allocation and the fairness of the prices that are achieved in a market. Prof. Yano received a B.A. in economics from The University of Tokyo in 1971 and a Ph.D. in economics from The University of Rochester in 1981.

Open Access This chapter is licensed under the terms of the Creative Commons AttributionNonCommercial-NoDerivatives 4.0 International License (http://creativecommons.org/licenses/bync-nd/4.0/), which permits any noncommercial use, sharing, distribution and reproduction in any medium or format, as long as you give appropriate credit to the original author(s) and the source, provide a link to the Creative Commons license and indicate if you modified the licensed material. You do not have permission under this license to share adapted material derived from this chapter or parts of it.

The images or other third party material in this chapter are included in the chapter's Creative Commons license, unless indicated otherwise in a credit line to the material. If material is not included in the chapter's Creative Commons license and your intended use is not permitted by statutory regulation or exceeds the permitted use, you will need to obtain permission directly from the copyright holder.

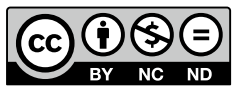

